\title{
Axenic Germination of Glomus intraradices in in vitro
}

\author{
K.S. Raghavendra*, P. Jones Nirmalnath and K.S. Jagadeesh \\ Department of Agricultural Microbiology, College of Agriculture, \\ University of Agricultural Sciences, Dharwad - 580 005, Karnataka, India \\ *Corresponding author
}

Keywords

Spore germination, Germ tube induction, Glomus intraradices, Root exudates.

\section{Article Info}

Accepted:

22 December 2019

Available Online:

20January 2020

\section{A B S T R A C T}

Arbuscular mycorrhizal (AM) fungi are obligate symbiont and integrate with most of terrestrial plants. AMF belongs to the phylum Glomeromycota that cannot complete their life cycle without establishing a functional symbiosis with host plant. In the present investigation, Glomus intraradices Spores were surface sterilized and transferred to different media viz., one per cent water medium agar medium, Murashige and Skoog medium. Modified Strulla Romand (MSR) medium and white's medium with root exudates of Agrobacterium rhizogenes MTCC-532 transformed hairy roots of chickpea. Surface sterilized spores were spread on the per Petri plate with five replications for germination test. The petriplates were incubated at $24^{0} \mathrm{C}$ under dark condition. Spore germination study revealed that germination and germ tube growth of $G$. intraradices was influenced by root exudates in all the medium. The results have clearly shown that the MSR medium incorporated with root exudates recorded the maximum spore germination (93.3 per cent) and the highest initiation of germ tube was recorded at $35 \mathrm{DAI}(61.05 \mathrm{~mm})$.

\section{Introduction}

An Arbuscular mycorrhizal fungus starts with the germination of propagules (i.e. spores, vesicles or colonized root fragments). These structures produce a limited amount of hyphae, which are capable of anastomosis. In absence of host plant, their growth is arrested. In presence of root signals viz., strigolactones, the growth and branching of hyphae is strongly stimulated and the fungus switch its development from the asymbiotic to the presymbiotic phase (Akiyama, 2007). Axenic germination of Glomus intraradices spore has so far not been achieved, it is obligate biotrophic. Spores of Glomus intraradices readily germinate in vitro with hyphae elongating for a relatively short period on various media.

Hyphal growth from germinating spores ceased before exhaustion of the spore reserves 
(Raman et al., 2001). Spore germination is the precondition of symbiosis with plants. During the pre-symbiotic phase, many factors, such as a rhizosphere environment, high flavonoid content, presence of soil microorganisms and plant cell suspension culture, can induce spore germination and promote hyphal growth without a host (Pearson et al.,, 1989; Graham et al., 1982).

In addition, root exudates can increase the length and degree of branching of AM fungi hyphae (Tamasloukht et al., 2003) and play an important role in plant-microbe interactions in the rhizosphere (Ahmed et al., 2013). In the study we have examined the germination of Glomus intraradices in different media with root exduates from the transformed hairy roots of chickpea.

\section{Materials and Methods}

An investigation was carried out to isolate native Glomus intraradices fungal isolates from the Sugarcane. These experiments were conducted during the year 2019-20 at Department of Agricultural Microbiology, University of Agricultural Sciences, Dharwad. Soil samples were collected from Sugarcane growing site located at N-16 $06^{\circ}$ 586"latitude; E longitude, and at an altitude of $653 \mathrm{~m}$ above mean sea level at yaragatti village of Belgaum district.

The soil samples were used to carry out the germination $t$ of Glomus intraradices in in vitro. Spores isolated from the rhizosphere soil were identified as Glomus intraradices after trap culturing them as described by (Patricia et al., 2009).

AM fungal spores were extracted and identified based on morphological features, viz., color, size, wall structure and hyphal attachment as described by Rodrigues and Muthukumar (2009).

\section{Morphology Identification}

The single spore was extracted from the respective funnels and mounted on clean glass slides in lacto phenol. The spore identification was mainly based on morphological features, viz., colour, size, wall structure and hyphal attachment as per the outline given by Schenk and Perez (1990) ; Rodrigues and Muthukumar (2009) and INVAM website http://invam caf.wuv.edu by Joe Mortan. Finally the spores were photographed under research stereomicroscope connected to a computer with digital image analysis software.

\section{Macro character}

The macro-characteristics viz, sporocarp, spore and subtending hypha were used to characterize the visual difference in the gross descriptive morphology of a species (walker, 1992).

\section{Micro character}

To have a more precise identification of AM fungi, the micro-characteristics viz., spore wall layer, texture and colour were studied as explained by Mehrotra and Mehrotra (1999) to differentiate among certain AM fungi using Visual difference in morphology of fungal hyphae and vesicles within the roots. The mounted spores were differentiated mainly based on morphology and nature of hyphal attached by referring the characteristics described above and identified spores were designated and tabulated.

\section{Standardization of hairy root induction in chickpea by in vitro technique.}

\section{Activation of bacterial strain}

The Agrobacterium rhizogenes MTCC-532 were obtained from Microbial Type Culture 
Collection (MTCC), Chandigarh, India was screened for their growth on different media $v i z$, Luria Bertani broth (LB), nutrient broth (NB) and yeast extract mannitol (YEM) broth. A loop full of A. rhizogenes MTCC-532 culture was inoculated into the broth and incubated at $25^{\circ} \mathrm{C}$ with $80 \mathrm{rpm}$ for $24 \mathrm{~h}$ in an temperature controlled centrifuge.

The growth of A. rhizogenes strain was estimated, by measuring at $600 \mathrm{~nm}$ using Nano drop (Thermo Scientific, USA). Based on the growth and density of the culture, the best media was selected for further study.

\section{Chickpea seeds for hairy roots induction}

The chickpea seeds of A-I variety were selected for in vitro hairy root induction by phytopathogenic bacterium, A. rhizogenes MTCC-532 by genetically transferring by different method of infections (Plate .1)

\section{Surface sterilization of seeds}

Chickpea seeds were surface sterilized with alcohol $(70 \% \mathrm{v} / \mathrm{v})$ for 1 minute and with sodium hypochlorite solution $(4 \% \mathrm{v} / \mathrm{v})$ for 10 minutes, followed by washing with sterile distilled water and finally soaked in sterilized distilled water overnight under dark condition.

Seeds were then placed in sterilized petriplates with wet filter paper under dark condition at $28^{\circ} \mathrm{C}$ for three days

No. of explants inducing hairy roots

Transformation frequency $=$

\section{Influence of different methods of agrobacterium rhizogenes induction of hairy roots.}

A lab experiment was conducted to study the influence of different methods of infection. A. rhizogenes (MTCC532) was infected to the radicle of the chickpea. Three days old seeding root was cut below epicotyl near the cotyledonary region and infection of $A$. rhizogenes by Cut the radical and smear with A. rhizogenes broth methods (Plate 1).

The roots from the three days old chickpea seedlings were subjected for sectioning at the hypocotyls region for the infection test.

\section{Preparation of co-cultivation}

After 7-10 days of incubation, the explants were checked for the production of hairy roots and growth of bacteria on the media. If the growth was observed, the explants were transferred to MS media enriched with the concentration (50 to $300 \mathrm{mg} / \mathrm{l}$ ) of cefotaxime. The sub culturing of explants will be to the fresh medium as above till the bacterial growth was completely arrested.

After the bacterial free growth was observed, the transformed roots were transferred to the fresh medium as above till the bacterial growth was completely eliminate.

The transformation rate was calculated as below:

Total No. of explants infected with A. rhizogenes 


\section{Surface sterilization of AMF spore}

Efficient sterilization process is the key factor for the success in the development of monoxenic AM fungal cultures. The spore of Glomus intraradices, which was identified in the present study was surfaced sterilized according to Becard and Piche (1992) as given below.

The spores collected from the wet sieving and decantation method was filtered in the sterilized filter unit (Tarsons memberane filter holder) through cellulose nitrate membrane with a 0.2 micro meter filter.

Spore was treated in four different sterilizing agents such as 90 per cent ethyl alcohol for one minute and two per cent calcium hypochlorite for one minute followed by 10 min in a mixture of two per cent Chloramine $\mathrm{T}$ and Two drops of Tween 20.

Spores were subsequently rinsed in 0.02 per cent streptomycin and 0.01 per cent gentamycin antibiotic solution. Ten psi pressure was applied with vaccum pump, the sterilization agents was filtered out in the receiver and leaving the spores alone in the memberane filter.

Spore present in the filter membrane was washed several times with sterile distilled water to remove the traces of sterilizing agent. There after aseptically the spores along with membrane was taken separately from membrane holder using sterile forceps and picked by viewing under stereomicroscope.

\section{Spore germination studies}

Surface sterilized spores were transferred to different media viz., one per cent water medium agar medium, Murashige and Skoog medium (Murashige and Skoog, 1962) Modified strulla Romand (MSR) medium (Declerck et al., 1996) and white's medium (Becard and Fortin, 1988) for germination test.

Agrobacterium rhizogenes MTCC-532 transformed hairy roots of chickpea was transferred to sterile distilled water and incubated at $24^{\circ} \mathrm{C}$ for 7 days. Roots exudates was collected and stored at $-20^{\circ} \mathrm{C}$ (Wang et al., 2015).

Two $\mathrm{ml}$ of roots exudates was transferred to the flask containing $100 \mathrm{ml}$ of testing media. $20 \mathrm{ml}$ of media enriched with root exudates were transfered into $90 \mathrm{~mm}$ diameter petriplate. Surface sterilized spores were spread on the petriplate @ twenty spores per Petri plate with five replications.

The petriplates were incubated at $24^{0} \mathrm{C}$ under dark condition. Spore germination was measured and expressed in percentage. The plates were observed at regular intervals under the stereomicroscope (Olympus SZX series) for spore germination.

The per cent germination was determined as detailed below.
AM spore germination $(\%)=$

No. of spores germinated

Total number of spores kept for germination x 100

in vitro condition by using different media with root exduates. The Spores were tentatively identified based on the morphological characters like size, shape,
In the present investigation, an attempt was made to germinate Glomus intraradices under

\section{Results and Discussion}


colour, spore wall layer, spore wall thickness, subtending hyphae and special features of the spores (Table. 1 and Plate. 2). In the present study the native AMF spore isolated from the sugarcane rhizosphere has been tentatively identified as Glomus intraradices. The colour of the spore ranged from brown to greyish yellow and the shape varied from globose to sub-globose with a spore size was $123 \mu \mathrm{M}$ with three wall layers.

Further, the native spore wall extending into the hyphal attachment forming an apparent cylindrical flare at the juncture with the hyphal attachment and the spore exhibited tiny notches on the surface. Our findings are also in accordance with the observations of Rodrigues and Muthukumar (2009). The development of the AMF starts with the germination of propagules (i.e. spores, vesicles or colonized root fragments). These structures produce a limited amount of hyphae, which are capable of anastomosis. In absence of host plant, their growth is arrested. However, in presence of host plant and signaling compounds like strigolactones, the germination propugules are stimulated (Akiyama, 2007).

Table.1 Morphological description of native Glomus intraradices from sugarcane rhizosphere soil

\begin{tabular}{|c|c|c|c|c|c|c|}
\hline Shape of Spores & $\begin{array}{l}\text { Colour of } \\
\text { spore }\end{array}$ & $\begin{array}{l}\text { Size of } \\
\text { spore }\end{array}$ & $\begin{array}{l}\text { Spore wall } \\
\text { Layer }\end{array}$ & $\begin{array}{l}\text { Spore wall } \\
\text { Thickness }\end{array}$ & Special feature & $\begin{array}{l}\text { Tentatively } \\
\text { identified }\end{array}$ \\
\hline $\begin{array}{l}\text { Globose } \\
\text { subglobose }\end{array}$ & $\begin{array}{l}\text { Brown } \\
\text { colour to } \\
\text { grey yellow }\end{array}$ & $123 \mu \mathrm{m}$ & Three layers & $\begin{array}{l}\mathrm{L} 1: 0.7 \mu \mathrm{m} \\
\mathrm{L} 2: 0.9 \mu \mathrm{m} \\
\mathrm{L} 3: 1.1 \mu \mathrm{m}\end{array}$ & $\begin{array}{lr}\text { Spores } & \text { Surface } \\
\text { pitted } & \text { found } \\
\text { with } & \text { small } \\
\text { notches } & \end{array}$ & $\begin{array}{l}\text { Glomus } \\
\text { intraradices }\end{array}$ \\
\hline
\end{tabular}

Table.2 Germination percentage of Glomus intraradices as influenced by different culture media

\begin{tabular}{|c|c|c|c|c|c|c|c|}
\hline \multirow[t]{2}{*}{ Media } & \multicolumn{7}{|c|}{ Per cent of spore germination } \\
\hline & $\begin{array}{c}\mathbf{5} \\
\text { (DAI) }\end{array}$ & $\begin{array}{c}10 \\
\text { (DAI) }\end{array}$ & $\begin{array}{c}15 \\
\text { (DAI) }\end{array}$ & $\begin{array}{c}20 \\
\text { (DAI) }\end{array}$ & $\begin{array}{c}25 \\
\text { (DAI) }\end{array}$ & $\begin{array}{c}30 \\
\text { (DAI) }\end{array}$ & $\begin{array}{c}35 \\
\text { (DAI) }\end{array}$ \\
\hline MS with Root exudates & 00 & 00 & 00 & 22.5 & 28.0 & 32.5 & 58.3 \\
\hline MSR with Root exudates & 00 & 00 & 00 & 28.7 & 42.5 & 60.8 & 73.5 \\
\hline Whites Media with Root exudates & 00 & 00 & 00 & 8.8 & 24.2 & 10.0 & 36.7 \\
\hline Water agar with Root exudates & 00 & 00 & 00 & 13.0 & 10.7 & 12.8 & 52.5 \\
\hline $\begin{array}{lll}\text { S.Em } \pm & \text { S }\end{array}$ & - & - & - & 1.07 & 1.27 & 1.65 & 1.70 \\
\hline C.D.(0.01) & - & - & - & 3.11 & 3.68 & 4.81 & 4.94 \\
\hline
\end{tabular}

Note: Mean No. of germinated spores. 


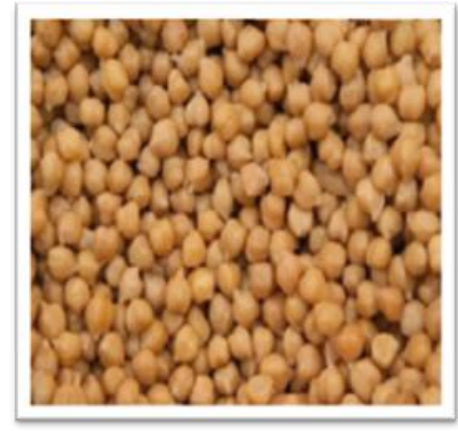

a. surface sterilization

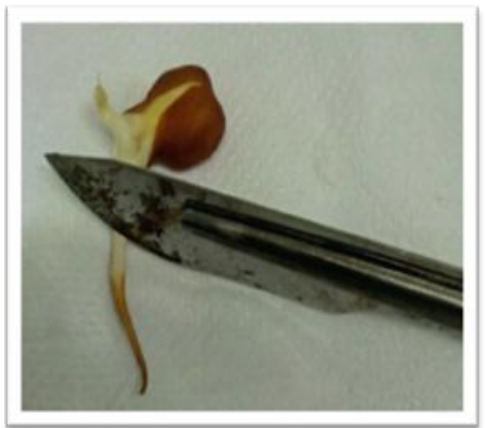

d. sectioning the radicle at hypocotyl region

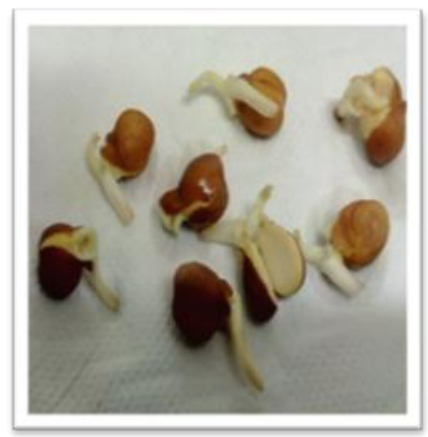

g. Elimination of Agrobacterium

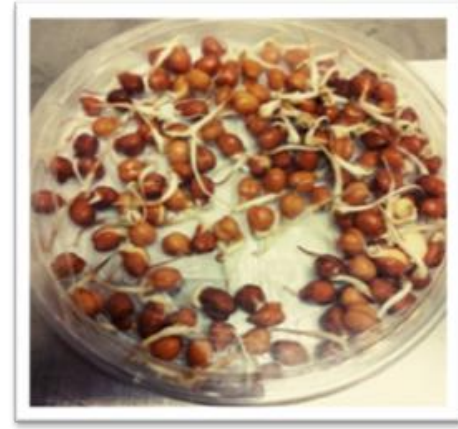

b. Germinating seeds

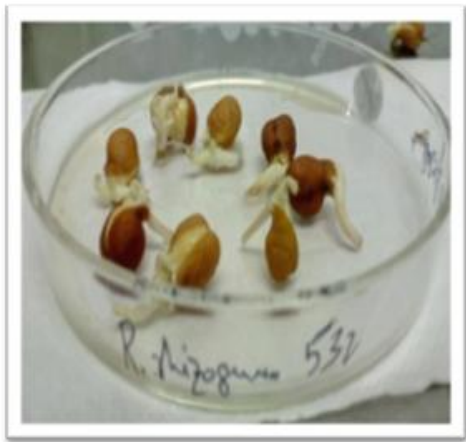

e. Agrobacterium infection

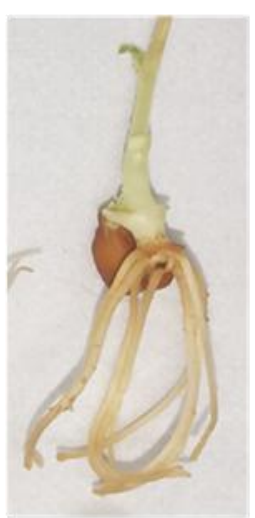

h. Initiation of hairy roots at the cut end region

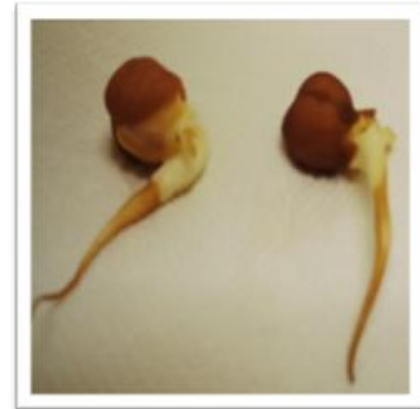

c. Sprouted chickpea seeds

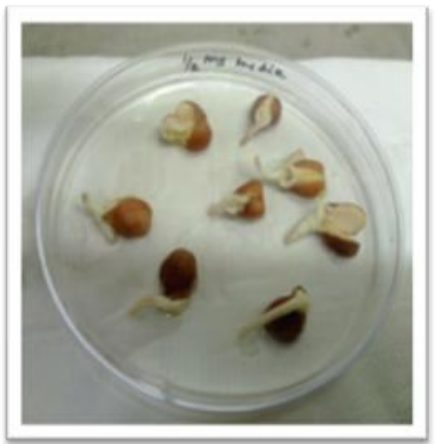

f. Co-cultivation of infected seeds

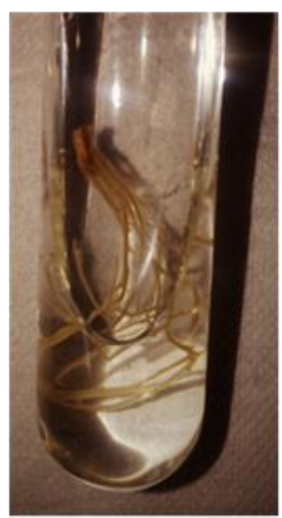

i. Roots exudates collected and stored at $-20^{\circ} \mathrm{C}$

Plate.1 Induction of hairy root by Agrobacterium rhizogenes MTCC-532. 
Table.3 Length of germ tube as influenced by different culture media

\begin{tabular}{|l|c|c|c|c|}
\hline \multirow{2}{*}{\multicolumn{1}{|c|}{ Media }} & \multicolumn{4}{|c|}{ Length of germ tube (mm) } \\
\cline { 2 - 5 } & $\mathbf{2 0}(\mathbf{D A I})$ & $\mathbf{2 5}(\mathbf{D A I})$ & $\mathbf{3 0}$ (DAI) & $\mathbf{3 5}$ (DAI) \\
\hline MS with Root exudates & 3.78 & 14.36 & 24.96 & 39.15 \\
\hline MSR with Root exudates & 11.64 & 23.89 & 45.92 & 61.05 \\
\hline Whites Media with Root exudates & 0.20 & 2.59 & 4.17 & 12.23 \\
\hline Water agar with Root exudates & 3.50 & 6.66 & 13.62 & 30.30 \\
\hline S.Em \pm & $\mathbf{1 . 9 8}$ & $\mathbf{5 . 8 4}$ & $\mathbf{8 . 3 0}$ & $\mathbf{1 1 . 8 4}$ \\
\hline C.D.(0.01) & $\mathbf{5 . 8 2}$ & $\mathbf{1 7 . 1 3}$ & $\mathbf{2 4 . 3 4}$ & $\mathbf{3 4 . 7 1}$ \\
\hline
\end{tabular}

Note: Mean No. of germinated spores.

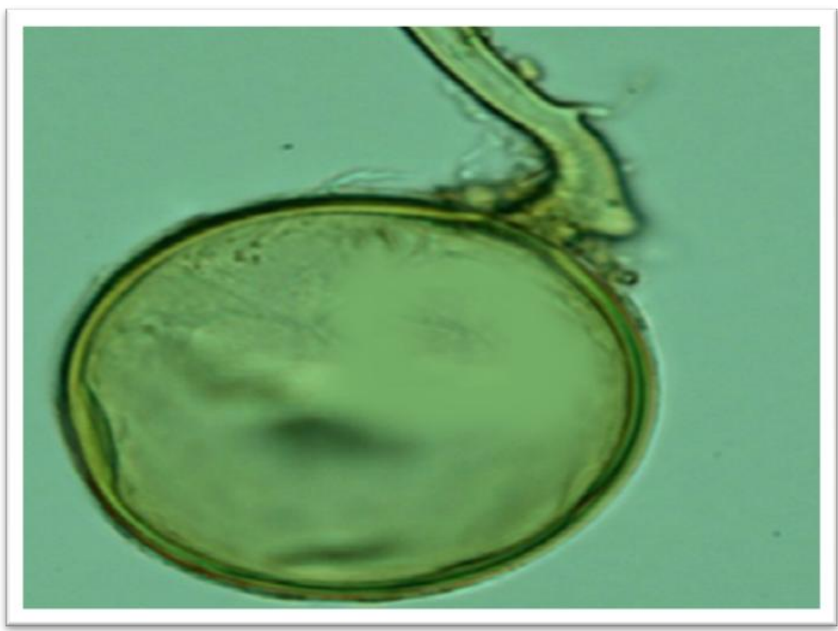

Plate.2 Native Glomus intraradices

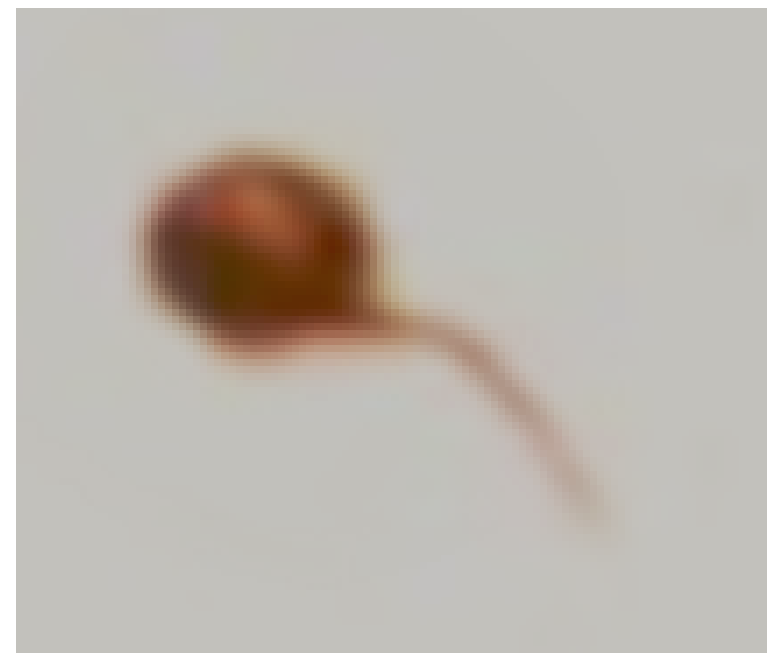


Plate.3 Spore germination

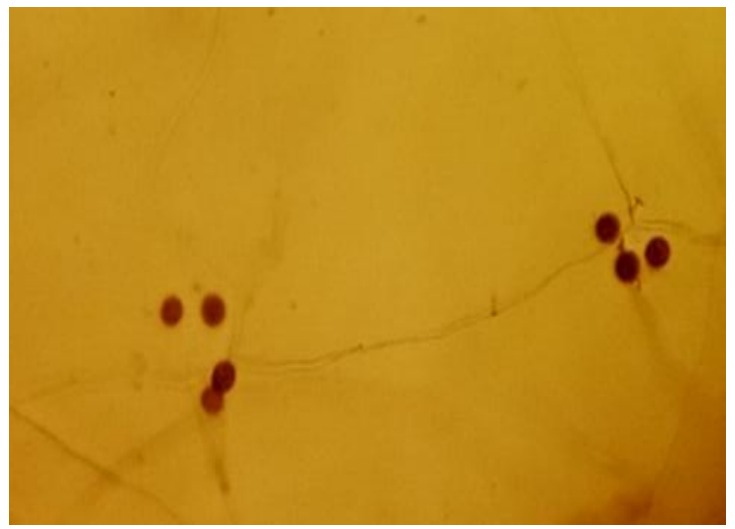

Plate.4 Germ tube of Glomus intraradices

The germination percentage of $G$. intraradices spores was evaluated and the results have indicated that the MSR medium recorded the maximum spore germination (93.3 per cent), followed by MS medium (58.3 per cent) at 35 DAI. The lowest spore germination was observed in White's medium (36.7 \%) (Table 2 and Plate 3). The germ tube of $G$. intraradices spores was evaluated. Among the different media, the MSR medium recorded the highest initiation of germ tube (11.64 mm, $23.89 \mathrm{~mm}, 45.92 \mathrm{~mm}$ and 61.05 $\mathrm{mm}$ at 20, 25, 30 and $35 \mathrm{DAI}$, respectively) compared to MS medium, water agar medium and the least germ tube was induced with whites medium (Table 3 and Plate. 4).

The increased spore germination and germ tube growth with modified MSR medium due to the presence of all major, minor nutrients and root exudates. The Spore germination and growth were better in the Modified Strullu Romand medium enriched with root exudates compared to control. Similar findings were also reported by Wang et al. (2015) that root exudates were proven better than glucose in inducing spore germination.

Paula et al. (1990) concluded that higher germination and mycelia growth of $G$. gigantean, G. margarita and Scutellospora heterogamy was observed when the MS medium was $10 \mathrm{X}$ diluted. The same observation was recorded by Hepper (1984), who reported that when spores of Acaulospora laevis were exposed to different $\mathrm{pH}$ levels the germination was higher at lower $\mathrm{pH}$. Furthermore, the nutrient concentration in the media are also known influence the AMF colonization in MSR medium, where $\mathrm{KH}_{2} \mathrm{PO}_{4}$ has been incorporated @ $410 \mathrm{mg} \mathrm{L}^{-1}$ compared to the MS medium lacking at $\mathrm{KH}_{2} \mathrm{PO}_{4}$.

Surface sterilization of AM spores is considered as one of the most important, which plays a critical role in spore germination as well in the formation of mycelia network. The control plates incubated without unsterilization spores resulted in 100 per cent contamination this was in agreement with the findings of Walley and Germida (1996), wherein, they have observed bacterial growth between the spore wall layers.

\section{Acknowledgement}

The authors are thankful to all the staff 
members of Dept. of Microbiology, University of Agricultural Science, Dharwad, Karnataka for their valuable support and guidance for the present study.

\section{References}

Ahmed, H., Anna,M., Andreas, V., Franz, H., Siegrid, S., 2013, Alterations in Root Exudation of Intercropped Tomato Mediated by the Arbuscular Mycorrhizal Fungus Glomus mosseae and the Soilborne Pathogen Fusarium oxysporum f.sp. Lycopersici. J Phytopathol. 161, 763-773

Akiyama, K., Matsuzaki, K. and Hayashi, H., 2005, Plant sesquiterpenes induce hyphal branching in arbuscular mycorrhizal fungi. Nature, 435: 824827

Atlas R. M., 1996, Handbook of Microbiological Media, 2nd Ed., CRC Press, New York.

Becard, G. and Fortin, J.A., 1988, Early events of vesicular-arbuscular mycorrhiza formation on $\mathrm{Ri}$ T-DNA transformed roots. New Phytol. 108: 211-218.

Bechard, G and Piche, Y., 1992. Establishment of vesicular arbuscular mycorrhiza formulaion on $\mathrm{Ri}$ T-DNA transformed roots. New Phytol., 108: 211-218.

Declerck, S., D.G. Strullu and C. Plenchette., 1996, In vitro mass multiplication of arbuscular mycorrhizal fungus, Glomus versiforme, associated with $\mathrm{Ri}$ T-DNA transformed carrot roots. Mycol. Res., 100:1237-1242.

Gerdemann, J. W. and Nicolson, T. H., 1963, Spores of mycorrhizal Endogone species extracted from soil by wet sieving and decanting. Trans. British Mycol. Soc., 46: 235-244.

Graham, J.H. 1982. Effect of citrus root exudates on germination of chlamydospores of the vesiculararbuscular mycorrhizal fungus Glom us epigaeum. Mycologia.74, 831-835

Hepper, C.M., 1984. Regulations of spore germination of the vesicular-arbuscular mycorrhizal fungus Acaulospora laevis by soil PH. Trans. Br. Mycol. Soc., 83:154-156.

Mehrotra, M. D. and Mehrotra, A., 1999, Siutability of potting mixture for VAM infection and spore population in root trainer rasied seedlimgs. Indian J. For., 22 (1): 49-52.

Murashige, T. and Skoog, F., 1962, A Revised Medium for Rapid Growth and Bio Assays with Tobacco Tissue Cultures. Physiologia

Plantarum. 15 (3): 473-497.

Ohms, R. E., 1957, A floatation method for collecting spores of a phycomycetous mycorrhizal parasite from soil. Phytopathology, 47: 751-752.

Patricia L. L, Sturmer, S. L. and Siqueira, J. O., 2009, Occurrence and diversity of arbuscular mycorrhizal fungi in trap cultures from soils under different land use systems in the amazon. Brazil. Brazilian J. Microbiol., 40: 111-121.

Paula, M.A., Reis, V. M. and Doberemer, J., 1991. Interactions of Glomus clarum with Acetobacter diaztrophicus in infection of swet potato and sweet sorghum. Biol. Fertil. Soils., 11:111115.

Pearson, G., Duma, G V., Gollotte, E., TahiriAlaoui, A., Gianinazzi, S. 1989. Cellular and molecular defence-related root responses to invasion by arbuscular mycorrhizal fungi. New Phytol. 133, 45-57

Raman, N., Sahadevan, C. and Srinivasan, V., 2001, Growth of AM fungi on In vitro root organ culture of Sorghum and sugarcane. Indian J. Exp. Biol., pp. 1293-1298.

Ridgway, H.J., Kandula, K. and Stewart, A., 
2004. Optimising production of carrot hairy roots. N. S. Plant Prot., 57:77-80.

Rodrigues, B. F. and Muthukumar, T., 2009, Arbuscular mycorrhizae of Goa, $A$ manual of Identification protocols, pp. 123-124.

Schenck, N. C and Perez, Y., 1990, Isolation and culture of VA mycorrhizal fungi, in: Isolation of Biotechnological organisms from Nature. (ed), D. P. Labeda, McGraw-Hill Book Co., New Yorks, New York, pp: 237-258.

Tamasloukht, M.B., Séjalon-Delmas, N., Kluever, A. 2003. Root factors induce mitochondrial- related gene expression and fungal respiration during the developmental switch from asymbiosis to presymbiosis in the arbuscular mycorrhizal fungus Gigaspora rosea. Plant Physiol. 131, 1-11.

Walker, C., 1992, Systematics and taxonomy of the arbuscular endomycorrhizal fungi a possible way forward. Agronomire, 12: 887-897.

Walley, F. L. and Germida, J.J., 1996. Failur to decontaminate Glomus Clarum NT4 spores is due to spore wall-associated bacteria. Mycorrhiza, 6:43-49.

Wang, Y., Tangl, S. and Jin. H., 2015, Effect of glucose, root exudates and $\mathrm{N}$ forms in mycorrhizal symbiosis using Rhizophagus intraradices. J. Soil Sci. Plant Nutrition, 15 (3): 726-736.

\section{How to cite this article:}

K.S. Raghavendra, P. Jones Nirmalnath and K.S. Jagadeesh. 2020. Axenic Germination of Glomus Intraradices in in vitro. Int.J.Curr.Microbiol.App.Sci. 9(01): 2387-2396.

doi: https://doi.org/10.20546/ijcmas.2020.901.272 